\title{
Fiber structure development in PS/PET sea-island conjugated fiber during continuous laser drawing
}

\author{
K. Sugawara , T. Ikaga , K. H. Kim ${ }^{1}$, Y. Ohkoshi ${ }^{1,2}$, K. Okada,
} H. Masunaga ${ }^{4}$, T. Kanaya ${ }^{5}$, M. Masuda ${ }^{6}$ and Y. Maeda 6

${ }^{1}$ Faculty of Textile Science and Technology, Shinshu University Japan.

${ }^{2}$ Division of Frontier Fibers, Institute for Fiber Engineering, Shinshu University,

Tokida 3-15-1, Ueda, Nagano prefecture, 386-8567, Japan.

${ }^{3}$ Material Science Laboratories, Toray Research Center, Inc, 3-3-7 Sonoyama, Otsu, Shiga 520-8567, Japan.

${ }^{4}$ Japan Synchrotron Radiation Research Institute, 1-1-1 Kouto, Sayo-cho, Sayo-gun, Hyogo 679-5148, Japan.

${ }^{5}$ Institute for Chemical Research, Kyoto University, Uji, Kyoto 611-0011, Japan. ${ }^{6}$ Toray Industries, Inc, 4845 Mishima, Shizuoka 411-8652, Japan.

Correspondence to: Y. Ohkoshi (E-mail: yokoshi@shinshu-u.ac.jp), K. H. Kim (E-mail: Khkim@shinshu-u.ac.jp) 


\begin{abstract}
The effect of draw ratio, molecular weight, and sea-island conjugated spinning with a polystyrene component on the fiber structure development of PET during laser drawing was analyzed by in-situ measurements with a $0.1 \mathrm{~ms}$ time resolution using an ultra-high luminance X-ray beam generated
\end{abstract} from a synchrotron equipped with an undulator. The fiber temperature increased from $120^{\circ} \mathrm{C}$ to $160-220^{\circ} \mathrm{C}$ during the structure development process. By drawing the higher molecular weight PET to a higher draw ratio, a larger amount of fibrillar smectic mesophase formed just after the onset of necking, and a more highly oriented crystal formed after the extinction of the smectic mesophase. Accordingly, fibers with higher strength and higher thermal shrinkage stress were obtained. On the other hand, by conjugated spinning with a PS component, the fiber temperature increased along with an increase in the drawing stress, but the stress applied to the PET component should have decreased. The amount of smectic mesophase formed by the conjugated-spinning process was drastically decreased, and no crystallization induction time was observed, unlike the other cases. Crystallization, particularly the growth of a lamellar crystal, was also promoted. Moreover, a higher Young's modulus, a higher yield stress, and a higher shrinkage stress were observed for the conjugated-spun and drawn fibers. Therefore, the fibrillar smectic mesophase seems to block the formation of the lamellar crystal. Furthermore, the resultant fibrillar structure tends to result in a higher strength, but a relatively lower modulus and yield strength of the fiber. 


\section{Introduction}

Poly (ethylene terephthalate) (PET) is a semi-crystalline polymer first synthesized by J. R.

Whinfield and J. T. Dickson in $1941 .{ }^{1}$ PET fiber is now the most widely used fiber primarily because of its good cost performance. The improvement of strength and modulus has always been a major research theme for synthetic fibers because their mechanical properties are their most important characteristics. Usually, the strength and modulus of synthetic fibers are far lower than their theoretical values. For example, the 1.1 GPa strength and $20 \mathrm{GPa}$ modulus of industrial grade PET fiber correspond to only $4 \%$ and $16 \%$ of the theoretical values. ${ }^{2}$ This is due to molecular weight limitations, incomplete molecular orientation and crystallinity, and particularly the inhomogeneity in the higher order structure of the fiber.

To produce high-strength synthetic fibers, one should generally aim for a high molecular weight and a high molecular orientation. ${ }^{3}$ Unfortunately, because a high molecular weight causes poor spinnability and drawability, it is difficult to form fibers with highly oriented molecular chains. Thus, to obtain high-strength fibers, a homogeneous chain network structure should be formed by melt spinning, followed by drawing to a high draw ratio. The term "melt structure control" ${ }^{-11}$ refers to methods of producing a homogeneous chain network structure, and bicomponent melt spinning has been investigated as one process of melt structure control. ${ }^{5,9,11}$ The bicomponent melt spinning 
process, in which two types of polymer are simultaneously extruded from a spinneret, produces a unique fiber structure that is substantially different from that of a melt spun homopolymer. ${ }^{5}$ The chain orientation relies heavily on the extensional stress at the solidification point in melt spinning, and therefore in bicomponent spinning the molecular orientation can be controlled by selecting an appropriate secondary component. For the bicomponent system of PET and polystyrene (PS) examined in this study, the activation energy of extensional viscosity and the glass transition temperature (Tg) for the PS were higher than in PET, so the stress applied in the spinline was mostly loaded onto the PS component, and the PET component was relaxed after the solidification of the PS component. Ultimately, the PET fiber could be stretched to a higher draw ratio, producing a high strength PET fiber.

Although PET is the most popular synthetic fiber and film, the relationship between and structure and properties is not yet fully understood. Many structure models ${ }^{12-16}$ have been proposed for semicrystalline polymers, but to accurately predict the properties of such polymers quantitatively on the basis of structural parameters remains problematic. A fiber structure, which consists of a fibrillar series of crystal and amorphous phases, is formed in the process of molecular chain extension, and this is followed by instant orientation-induced crystallization during melt spinning and/or drawing. Our research group has quantitatively investigated the relationship between fiber structure and properties by clarifying the fiber structure formation process. The fiber structure formation process is 
both academically and industrially significant because of the instant self-orientation of polymeric molecules and processes for manufacturing polymeric goods, respectively. A mesophase of PET, which is a precursor of the crystal structure developed during the fiber structure formation process, has also been investigated in several previous research efforts. Imai et al. ${ }^{17}$ proposed an ordering process of crystallization induction prior to crystal nucleation, in which the ordering of chain segments increases the chain rigidity, and then the crystallization begins once a certain level of order is achieved. Kolb et al. ${ }^{18}$ described PET fiber structure development during melt spinning according to in situ X-ray diffraction measurements with a time resolution of 0.33-0.6 ms. Kawakami et al. ${ }^{19}$ observed, in batch drawing, a series of strain-induced phase transitions using X-ray diffraction measurements, including phase transitions from an isotropic slush to an oriented slush, from the oriented slush to smectic $\mathrm{C}$, from smectic $\mathrm{C}$ to quasi-smectic $\mathrm{A}$, and from quasi-smectic $\mathrm{A}$ to a triclinic crystal. Mahendrasingam et al. ${ }^{20}$ examined fiber structure development after batch drawing using X-ray diffraction data recorded over $40 \mathrm{~ms}$. Unlike the continuous drawing process, the laser-drawing process has allowed the successful measurement of neck-deformation ${ }^{21}$ and temperature $^{22}$ profiles, because the necking location was almost stationary as the fiber was heated rapidly and homogeneously by $\mathrm{CO}_{2}$ laser irradiation. In continuous drawing, fiber structure development has been successfully characterized in situ with a time resolution of less than $1 \mathrm{~ms}$ using an ultra-high luminance synchrotron radiation beam at SPring- $8 .{ }^{23-26}$ As a result, a meridian 
(001') diffraction of the smectic mesophase was observed before the formation of the crystal phase.

The fibrillar smectic mesophase can be regarded as the mother structure of the microfibril that carries any external stress applied to the fiber, and is therefore important in determining the mechanical properties of the resultant fiber. Therefore, measurements were carried out to analyze the relationship between the fiber production conditions, fiber structure development, and the properties of the resultant fibers. Kim et al. ${ }^{26}$ analyzed the effect of molecular weight on PET fiber structure development. However, because the time resolution was limited to approximately $0.5 \mathrm{~ms}$ by the use of a bending magnet light source, the molecular weight dependence on the amount of smectic mesophase observed in the initial stages of fiber structure development, which occupy less than 1.0 ms, could not be clearly observed.

The X-ray beam used in this study was supplied by a synchrotron equipped with an undulator, which can supply an X-ray beam that is thousands of times brighter than the bending magnet system. By using this X-ray source, not only could WAXD and SAXS images with improved S/N ratios be obtained in a few seconds of exposure time, but high-precision measurements with a $0.1 \mathrm{~ms}$ time resolution were also possible. This study analyzed the effects of conjugated spinning with a PS component, the molecular weight of the PET, and the draw ratio on the initial stages of PET fiber structure development. 


\section{Experimental}

\subsection{Sample}

Sea-island-type PS/PET conjugated fibers with 1000 PET islands were prepared, along with single-component PET fibers. PET polymers with intrinsic viscosities (IV) of 1.2 and $0.6 \mathrm{dlg}^{-1}$ were provided by Toray Industries, and the PS polymer was provided by PS Japan G-430. A conjugate-spun fiber called "S-PET", $90 \pm 1 \mu \mathrm{m}$ in diameter, was extruded from a 0.7 -mm-diameter $(\mathrm{L} / \mathrm{D}=3)$ single-hole spinneret at $290^{\circ} \mathrm{C}$ at a throughput rate of $6.7 \mathrm{gmin}^{-1}$. This fiber contained a $75 \%$ weight fraction of IV $0.6 \mathrm{dlg}^{-1} \mathrm{PET}$, and was taken up at $830 \mathrm{~m} \mathrm{~min}^{-1}$. On the other hand, single-component spun fibers $89 \pm 1 \mu \mathrm{m}$ in diameter were extruded from a 0.7 -mm-diameter $(\mathrm{L} / \mathrm{D}=3)$ single-hole spinneret at a throughput rate of $5.0 \mathrm{~g} \mathrm{~min}^{-1}$, and taken up at $390 \mathrm{~m} \mathrm{~min}^{-1}$. The two types of single-component fibers, "L-PET" and "H-PET" as shown below, were made from PET pellets of $\mathrm{IV}=0.6$ and $1.2 \mathrm{dlg}^{-1}$ at extrusion temperatures of $280^{\circ} \mathrm{C}$ and $290^{\circ} \mathrm{C}$, respectively. Only an amorphous halo was observed for all as-spun fibers in WAXD measurements, and the birefringence of the as-spun fibers was approximately 0.01 .

\subsection{In situ Measurements}

The in situ measurement system used in this study is schematically illustrated in Figure 1. Fibers fed continuously from a feed roller were heated by $\mathrm{CO}_{2}$ laser irradiation from three directions, drawn 
by the speed difference of the rollers, and taken up by a take-up roller. The drawing tension was measured using a tension meter (HS-1500S EIKO SOKKI Co., Ltd.) with a 100 gf tension pickup equipped between the neck-drawing point and the take-up roller. The drawing stress was calculated from the drawing tension and the diameter of the drawn fiber. The $\mathrm{CO}_{2}$ laser (PIN-30R ONIZUKA GLASS Co., Ltd.) had a rated output of $30 \mathrm{~W}( \pm 5 \%)$, a wavelength of $10.6 \mu \mathrm{m}$, a beam diameter of 6 $\mathrm{mm}$, a divergence angle of less than $1.0 \mathrm{mrad}$, and random polarization. The drawing conditions are shown in Table 1. Each fiber was drawn at both the maximum and minimum draw ratios for stable neck drawing by varying the fiber feeding speed. The laser power for each set of conditions was determined in order to minimize the fluctuation of the drawing point. The minimum draw ratio is strongly related to the natural draw ratio (NDR) of as-spun fibers as listed in table 1, but somewhat larger than the NDR.

Because the necking position can be fixed within a short range by the laser irradiation ${ }^{23-26}$, the fiber structure development process after necking can be observed by WAXD/SAXS measurements with the irradiating X-ray beam aimed a certain distance $(D)$ away from the necking point. The elapsed time after necking was obtained by dividing the distance $D$ by the fiber running speed. The distance $D$ was measured in a video image obtained coaxially with the X-ray beam. Because both the X-ray irradiation point and the neck-drawing point during the measurement were observed in the video image obtained from the CCD camera (Watec Co., Ltd. WAT-232S type), the distance could be 
determined accurately. On the other hand, for elapsed times of over $1.2 \mathrm{~ms}$, the necking point was outside the video image. In this case, the distance was determined from the shift of the x-axis stage on which the laser irradiation system was installed. The time resolution of the measurement was estimated from the position resolution $W_{X-r a y}$ divided by the fiber running speed, and the $W_{X-r a y}$ was calculated from the fluctuation width of the necking point $\left(W_{\text {deform }}: 0.07-0.11 \mathrm{~mm}\right)$, the width of the necking point $\left(W_{\text {neck }}: 0.07-0.13 \mathrm{~mm}\right)$, and the width of the $\mathrm{X}$-ray beam ( $\mathrm{W}_{\text {beam }}: 0.13 \mathrm{~mm}$ ), as shown in equation $1 . W_{\text {neck }}$ and $W_{\text {deform }}$ were determined together with the average necking position by analysis of the video image. The obtained time resolution for this study was 0.09-0.12 ms.

$$
W_{X-\text { ray }}=\sqrt{{W_{\text {beam }}^{2}}^{2}+W_{\text {neck }}^{2}+W_{\text {deform }}^{2}}
$$

The synchrotron X-ray beam used in this study was provided by SPring-8 BL03XU (FSBL), with an undulator to obtain an ultrahigh power X-ray beam. The wavelength was $0.10 \mathrm{~nm}$, and the beam size was $0.04 \mathrm{~mm}$ vertically and $0.13 \mathrm{~mm}\left(W_{\text {beam }}\right)$ horizontally. The camera lengths of the WAXD and SAXS measurements were $90 \mathrm{~mm}$ and $1743 \mathrm{~mm}$, and their patterns were obtained simultaneously using a $1032 \times 1032$ pixel $(50 \mu \mathrm{m} /$ pixel $)$ flat-panel detector exposed for $0.6 \mathrm{~s}$, and a $3000 \times 3000$ pixel $(100 \mu \mathrm{m} /$ pixel $)$ imaging plate exposed for $30 \mathrm{~s}$, respectively. The camera length 
was calibrated using silver behenate. The background due primarily to air scattering was subtracted from all measured patterns. And for the S-PET patterns, the effect of the PS component was minimized by subtracting a PS halo in addition. The scattering pattern of PS halo was measured from a $100-\mu m$-thick PS film, and was subtracted from the S-PET patterns compensated with mass fraction and irradiation volume of X-ray beam.

\subsection{Birefringence}

The birefringence $\Delta n$ was measured using a polarized microscope (BX51-33POC, Olympus Co., Ltd.) equipped with a $546 \mathrm{~nm}$ monochromic filter. Tricresyl phosphate was used as an immersion oil. The average and standard deviation for each fiber was calculated every 10 samples. The birefringence of S-PET could not be measured because of strong scattering from the interface between the PS and PET components.

\subsection{Thermal and Mechanical Measurements}

The mechanical, thermal, and thermomechanical properties of the drawn fibers were evaluated by tensile test, DSC, and TMA measurements, respectively. Before the measurements, approximately 98\% of the PS component of the PS/PET fiber was extracted using carbon tetrachloride. The strength, elongation, and Young's modulus of the fibers were measured using an Autograph AGS-X (Shimazu 
Co. Ltd.) equipped with a $50 \mathrm{~N}$ load cell and an air chuck. The sample length and elongation rate were $40 \mathrm{~mm}$ and $100 \% / \mathrm{min}$, and the average and standard deviation for each fiber was calculated every 10 samples. The fineness was calculated by the throughput rate, take-up speed, draw ratio, and mass fraction of PET component. A Thermoplus DSC8230 (Rigaku Co., Ltd.) was used for the DSC analysis. The scanning rate and sampling cycle were $10 \mathrm{~K} / \mathrm{min}$ and $1 \mathrm{~s}$, respectively. The latent heat of cold crystallization $\Delta H_{c}$ and melting $\Delta H_{m}$ were evaluated from the obtained DSC curve, and the crystallinity $X_{\mathrm{c}}$ was calculated using the crystal melting enthalpy $\Delta H^{0}{ }_{m}=135 \mathrm{~kJ} / \mathrm{kg} \cdot{ }^{27} \mathrm{~A}$ TMA/SS6100 (SII nanotechnology Co. Ltd.) was used for the TMA analysis. The sample length was $10 \mathrm{~mm}$, and the heating rate was $10 \mathrm{~K} / \mathrm{min}$.

\section{Results and Discussion}

\subsection{Fiber Temperature Profiles}

Fiber temperature profiles were estimated using an energy balance equation, which has been previously confirmed to agree with measured profiles. ${ }^{23}$ The absorption coefficients and the specific heat of PET and PS are $11.49^{22}$ and $6.40 \mathrm{~mm}^{-1}$, and 1.17 and $1.22 \mathrm{kJK}^{-1} \mathrm{~kg}^{-1}$, respectively, and those of the PS/PET fiber were estimated from their volume fractions. The absorption coefficient for PS was estimated from IR absorbance measurements of PS films $15-200 \mu$ m thick, using the Okumura procedure $^{22}$, and the heat transfer coefficient was estimated from the Kase and Matsuo formula. ${ }^{28}$ 
The heat of crystallization was also estimated from the crystallinity $X_{\mathrm{c}}$ of the drawn fiber, as obtained by DSC measurement in Section 2.4, and the crystallization rate obtained in 3.4.

Estimated fiber temperature profiles are shown in Figure 2. The horizontal axis shows the distance $D$ from the necking location and the corresponding elapsed time. The fiber temperature was increased by the laser irradiation, and when the fiber approached its glass transition temperature, the fiber temperature underwent a rapid increase to over $120^{\circ} \mathrm{C}$ due to the plastic deformation of necking. The temperature continued to increase after necking because of the laser irradiation and the heat of crystallization, reaching a maximum temperature of $160-220^{\circ} \mathrm{C}$ at the edge of the laser beam, and was then cooled by the surrounding air. For all fibers, the fiber were yielding around the glass transition temperature of PET. In more detail, the temperature just before necking decreased with increasing draw ratio, while the temperature just after necking and the maximum temperature increased with increasing draw ratio. The increase in temperature jump for H-PET was larger than for L- or S-PET. And the S-PET showed the higher temperature than the others after necking.

As mentioned above, although the temperature profile should be affected by fiber running speed, laser power, drawing stress, and so on, the temperature profile before the necking point was not changed so much. It is because the necking point moved to upstream or downstream so as to cancel the change of temperature profile referred to the necking point. The change in temperature profile with increasing draw ratio can be explained by the drawing stress; that is, a larger drawing 
stress led to both earlier yield at a lower temperature and a larger temperature jump at the necking point. The larger temperature jump for H-PET and S-PET also corresponded to the higher drawing stress. And the higher drawing stress for S-PET indicates that the 25\% of PS component carried the more stress than the low molecular weight PET component at the necking point, because the PS component needed to be yield below its glass transition temperature.

\subsection{Structure and Properties of Drawn Fiber}

The birefringence and thermomechanical properties of various drawn fibers are presented in Table 2. The birefringence of all drawn fibers exceeded 0.16. Higher birefringence, crystallinity, strength, Young's modulus, and thermal shrinkage stress were observed at higher draw ratios. For H-PET, higher cold crystallization temperatures of the as-spun fiber and higher maximum shrinkage temperatures of the drawn fibers were observed. Lower birefringence and Young's modulus were observed for fibers drawn at the lowest stable draw ratio, while higher strength and Young's modulus were observed for the highest stable draw ratio. Despite the higher drawing temperature, the drawn H-PET fibers had lower crystallinity than L-PET. These phenomena can be explained by the restriction of molecular motion with increasing entanglement. For S-PET, the drawn fibers had obviously higher crystallinity, shrinkage stress, and Young's modulus than L-PET. The PET component in S-PET should be drawn at a higher temperature under a lower stress, as described in 
Section 3.1. The higher drawing temperature should accelerate the growth of the lamellar crystal, resulting in a higher Young's modulus of the drawn fiber.

\subsection{WAXD Patterns}

WAXD patterns obtained from the drawing line are shown in Figure 3. The amorphous halo was concentrated along the equatorial direction by the drawing. The streak-like diffraction of smectic (001') appeared on the meridional direction, reaching a maximum intensity approximately $0.2 \mathrm{~ms}$ after necking, and almost vanished by $0.8 \mathrm{~ms}$. The streak-like profile indicates a fibrillar shape of the smectic mesophase that was strongly oriented along the fiber axis. ${ }^{25}$

A representative intensity profile is shown in Figure 4. The peak position and integrated intensity of ( $\left.001^{\prime}\right)$ diffraction were obtained by Gaussian peak fitting. The integrated intensity, normalized by that of the equatorial diffractions $\left(2 \theta=8-21^{\circ}\right)$, is shown in Figure 5, and the d-spacing calculated from the peak position is shown in Figure 6. The integrated intensity increased with increasing draw ratio and molecular weight, and decreased with increasing PS conjugation. Moreover, the maximum intensity for S-PET was observed for a shorter elapsed time. On the other hand, all of the d-spacings decreased with increasing elapsed time, and shorter spacings were observed for H-PET and S-PET than for L-PET.

The strong (001') diffraction observed for both high draw ratio and high molecular weight 
indicates that the higher drawing stress led to a larger fraction of the smectic mesophase, which consisted of extended molecular chain bundles, resulting in higher strength drawn fibers. On the other hand, the vanishing time for the smectic mesophase became shorter at higher draw ratios, and longer at higher molecular weights. This is probably because the increase in draw ratio accelerated the orientation-induced crystallization, while the increase in molecular weight led to a longer relaxation time. The longer vanishing time of ( $\left.001^{\prime}\right)$ diffraction for the higher molecular weight was reported previously ${ }^{26}$, but no comment was made regarding the effect on diffraction intensity. The clear observation of the amount of smectic mesophase present in this work was enabled by drastic improvements in time resolution and $\mathrm{S} / \mathrm{N}$ ratio of the obtained data resulting from the use of the undulator beamline. Meanwhile, the higher fiber temperature and lower applied stress to the PET component of S-PET should reduce the amount of smectic mesophase, which vanished at a shorter elapsed time. The effect of PS conjugated spinning may also suppress the formation of the smectic mesophase because the lower spinning stress applied to the PET component results in a more uniform network structure of entanglement, which has been reported as a method of melt structure control. ${ }^{28}$ That is to say, when drawing a more uniform network, a more uniform stress is applied to the molecular chains, which means a lower stress is applied to the molecular chains.

For all cases, applying more stress to the PET component should increase the amount of smectic mesophase formed. 


\subsection{Crystallinity and Crystallite Size}

Crystal development was evaluated using the crystallinity index ${ }^{25}$, which is defined as the integrated intensity fractions of (010), (-110), and (100) diffraction in the equatorial profile. Figure 7 shows the obtained crystallinity index and the results of a simulation based on an adapted Avrami-like equation ${ }^{25}$, which was in good agreement with the experimental data. The obtained crystallization rates had no obvious differences, whereas S-PET clearly had a shorter crystallization induction time than the other materials. This was probably a result of the drastic decrease in the (001') intensity of S-PET described in Section 3.3, because the crystallization induction time corresponds fairly well to the time at which the smectic mesophase begins to be observed. This indicates that the formation of the smectic mesophase clearly inhibits the orientation-induced crystallization, specially preventing the formation of the lamellar crystal results in the formation of a long-period structure.

The crystallite size was estimated from the width of the equatorial diffractions. Scherrer's formula, with a constant of 0.918 , was used for this estimation. The obtained crystallite sizes are shown in Figure 8. Larger crystallite sizes were observed for H-PET and S-PET than for L-PET for a normal direction of (010), and the size along the (100) direction increased with increasing elapsed time for all cases. 


\subsection{Crystal Orientation}

The crystal orientation factor was obtained for the (010), (-110), and (100) equatorial diffractions, with their intensity profile along the inclination angle, because the inclination angle is almost equal to the azimuthal angle for equatorial diffraction. The profiles were fitted by the summation of two equatorially symmetrical peaks. A Pearson VII type profile, denoted in equation 2, was assumed for each peak, where $\varphi_{\mathrm{p}}, \tau$, and $m=2$ are the peak angle, full width at half maximum, and form factor of the peak, respectively. Assuming an orientation axis tilt in the $(-230)$ plane,${ }^{29}$ he crystal orientation factor to the orientation axis was obtained for each diffraction, and the tilt angle $t$ was obtained for the peak angles of the (010) and (100) diffractions. ${ }^{23}$ The lattice constants $a=0.452 \mathrm{~nm}, \quad b=0.598$ $\mathrm{nm}, \quad c=1.077 \mathrm{~nm}, \alpha=101^{\circ}, \beta=118^{\circ}$, and $\gamma=111^{\circ} 30$ were used for the calculation.

$$
I(\phi)=-\frac{I_{0}}{\left\{1+4\left(\frac{\phi-\phi_{p}}{\tau}\right)^{2}\left(2^{\frac{1}{m}}-1\right)\right\}^{m}}
$$

The crystal orientation factor and tilting angle are shown in Figures 9 and 10, respectively. The crystal orientation factor increased rapidly within the $1.0 \mathrm{~ms}$ after necking, and continued to increase after that. The higher draw ratio caused a higher orientation factor, and the PS conjugation showed a high crystal orientation factor at the lower draw ratio, whereas the tilt angle decreased with 
increasing draw ratio and PS conjugation. It is interesting that even though the drawing stress applied to the PET component was presumably decreased by the PS conjugation, the crystal orientation increased with decreasing tilt angle. This seems to be caused by the "melt structure control" effect of conjugated spinning. It has been reported ${ }^{9,11}$ that higher strength fibers can be obtained by drawing under a lower drawing stress for conjugated-spun fibers than for single-component-spun fibers, and this effect was explained by the more uniform network structure of the molecular chain. ${ }^{31}$ This effect seems to also apply in the present case; that is, despite the lower drawing stress applied to the molecular chain network, a more ordered network structure was formed, resulting in well-oriented lamellar crystals after crystallization at higher temperatures.

\subsection{SAXS Pattern}

SAXS patterns are shown in Figure 11. An x-shaped pattern appeared just after necking, and changed to a 4-point pattern after $0.3 \mathrm{~ms}$. With increasing elapsed time, the intensity of the 4-point pattern increased along with the intensity of the overlapping meridional 2-point pattern. The $\mathrm{x}$-shaped pattern was obvious at the lower draw ratio, and was particularly distinct for S-PET, whereas the $\mathrm{x}$-shaped pattern was observed for a longer elapsed time, $0.58 \mathrm{~ms}$, with the higher draw ratio and for H-PET. The $\mathrm{x}$-shaped pattern was also observed for the high-speed spun fiber ${ }^{32,33}$ and the edge image of a PET film drawn at $100^{\circ} \mathrm{C} .{ }^{34}$ Funai et al. ${ }^{35}$ proposed the zig-zag fibril to explain 
this pattern, but the structuralorigin of the pattern remains unclear.

Figure 12 shows an intensity profile parallel to the equator passing through the 4-point peak. By applying Gaussian peak fitting, the profile can be separated into 4-point and 2-point peak fractions. The obtained 2-point fraction is shown in Figure 13. Even though the fraction less than $1.0 \mathrm{~ms}$ fluctuated because the scattered intensity was weak, it settled at a relatively constant value after that. A higher 2-point fraction was observed at the higher draw ratio and for S-PET. However, for the S-PET only, the 2-point fraction tended to increase gradually after $1.0 \mathrm{~ms}$, after the primary crystallization was almost complete. This seems to indicate the formation of a lamellar crystal perpendicular to the fibril axis, which corresponds to the higher crystal orientation factor and lower tilt angle of the S-PET.

The migration of the 4-point peak position is shown in Figure 14. The peak position of the $\mathrm{x}$-shaped pattern, which was not a streak but already a peak just after necking, is also plotted for S-PET drawn to the lower draw ratio. The peak moved to a higher angle on the $\mathrm{x}$-shaped pattern until $0.36 \mathrm{~ms}$, when the $\mathrm{x}$-shaped pattern transformed into the 4-point pattern. After the transformation, the peak of the 4-point pattern moved to a higher meridional angle but a lower equatorial angle with the orientation-induced crystallization. This behavior seems to indicate that the crystal embryo formed on the shear band corresponding to the $\mathrm{x}$-shaped pattern transformed into a lamellar crystal that grew in the lateral direction. 
The equatorial and meridional peak angles at the same elapsed time both decreased at the higher draw ratio, and the same tendency was observed for H-PET. Furthermore, for H-PET, the change in peak position, particularly the change of equatorial peak angle, was very small. In contrast, larger changes in both equatorial and meridional peak angles were observed for S-PET. Connecting these results with the WAXD results, the higher draw ratio and higher molecular weight causes thicker fibrils and fewer crystallites, whereas the PS conjugation causes thinner fibrils and more crystal embryos, which develop into the lamellar crystal.

\section{Conclusion}

Structure development during the laser drawing of PET fibers was analyzed by in-situ X-ray measurements with a focus on the effects of draw ratio, molecular weight, and conjugated spinning with a PS component. By using an ultra-high luminance X-ray source of undulator synchrotron radiation, high $\mathrm{S} / \mathrm{N}$ ratio patterns were obtained with a $0.1 \mathrm{~ms}$ time resolution.

The fiber temperature increased from $120^{\circ} \mathrm{C}$ to $160-220^{\circ} \mathrm{C}$ during the structure development. The higher drawing stress caused the formation of more smectic mesophase, more oriented crystals, and higher crystallinity. A stronger meridional SAXS peak corresponding to a lamellar structure was observed from the beginning of structure formation. These structural features as well as the higher molecular orientation should affect the properties of the drawn fiber, leading to higher strength, 
higher modulus, and higher peak temperature of the thermal shrinkage stress. Furthermore, the effect was stronger for a higher drawing ratio and with higher molecular weight PET.

In conjugated spinning with a PS component, the higher drawing stress led to a higher fiber temperature, so the drawing stress applied to the PET component should be lower. The drastic decreases in the amount of smectic mesophase formed and in the crystallization induction time were probably caused by the decrease in applied stress. As a result, highly oriented lamellar crystals seemed to form preferentially from the initial stages of crystallization in the drawing of conjugated spun fiber. In summary, applying more stress to the PET component caused the formation of more smectic mesophase but inhibited the formation of lamellar crystal in the laser drawing process. As a result, the fiber produced under a higher applied stress manifested a higher tensile strength but a lower Young's modulus. 


\section{References}

[1] J. R. Whinfield, J. T. Dickson, British Patent, 1941, 578079 to ICI.

[2] T. Kunugi, T, Ohta, K. Yabuki, High-Strength High-Modulus Fibers (in Japanese), Kyoritsu Shuppan, 1988, 22.

[3] A. Ziabicki, Text. Res. J., 66 (1996) 705.

[4] T. Kikutani, J. Radhakrishnan, S. Arikawa, A. Takaku, N. Okui, X. Jin, F. Niwa, Y. Kudo, J. Appl. Polym. Sci., 62 (1996) 1913.

[5] J. Radhakrishnan, T. Kikutani, N. Okui, Text. Res. J., 67 (1997) 684.

[6] H. J. Jeon, H. Ito, T. Kikutani, N. Okui, M. Okamoto, J. Appl. Polym. Sci., 70 (1998) 665

[7] W. Takarada, H. Ito, T. Kikutani, N. Okui, J. Appl. Polym. Sci., 80 (2001) 1575.

[8] M. Masuda, Y. Funatsu, K. Kazama, T. Kikutani, Sen’i Gakkaishi, 60 (2004) 338.

[9] K. Nakata, Y. Ohkoshi, Y. Gotoh, M. Nagura, Y. Funatsu, T. Kikutani, Sen'i Gakkaishi, 60 (2004) 352.

[10] M. Masuda, W. Takarada, T. Kikutani, Int. Polym. Process., 25 (2010) 159.

[11] K. Nakata, F. Nakamura, Y. Ohkoshi, Y. Gotoh, M. Nagura, A. Hamano, S. Takada, T. Kikutani, Int. Polym. Process., 27 (2012) 386.

[12] D. A. Zaukelies, J. Appl. Physics, 33 (1962) 2797. 
[13] D. R. Beresford, H. Bevan, Polymer, 5 (1964) 247.

[14] P. F. Dismore, W. O. Statton, J. Polym. Sci. Part B: Polym. Letters, 2 (1964) 1113.

[15] A. Peterlin, P. Ingram, H. Kiho, Die Makromolekulare Chemie, 86 (1965) 294.

[16] R. H. Somani, L. Yang, L. Zhu, B. S. Hsiao, Polymer, 46 (2005) 8587.

[17] M. Imai, K. Kaji, T. Kanaya, Y. Sakai, Phys. Rev. B, 52 (1995) 12696.

[18] R. Kolb, S. Seifert, N. Stribeck, H. G. Zachmann, Polymer, 41 (2000) 2931.

[19] D. Kawakami, B. S. Hsiao, C. Burger, S. Ran, C. Avila-Orta, I. Sics, T. Kikutani, B. Chu, Macromolecules, 38 (2005) 91.

[20] A. Mahendrasingam, C. Martin, W. Fuller, D. J. Blundell, R. J. Oldman, J. L. Harvie, D. H. MacKerron, C. Riekel, P. Engstrom, Polymer, 40 (1999) 5553.

[21] W. Okumura, T. Kanegae, Y. Ohkoshi, Y. Gotoh, M. Nagura, Int. Polym. Process., 18 (2003) 46.

[22] W. Okumura, T. Yamaguchi, Y. Ohkoshi, Y. Gotoh, M. Nagura, Int. Polym. Process., 17 (2002) 24.

[23] T. Yamaguchi, K. H. Kim, T. Murata, M. Koide, S. Hitoosa, H. Urakawa, Y. Ohkoshi, Y. Gotoh, M. Nagura, M. Kotera, K. Kajiwara, J. Polym. Sci.: Part B: Polym. Phys., 46 (2008) 2126.

[24] K. H. Kim, T. Yamaguchi, Y. Ohkoshi, Y. Gotoh, M. Nagura, H. Urakawa, M. Kotera, T. Kikutani, J. Polym. Sci.: Part B: Polym. Phys., 47 (2009) 1653.

[25] K. H. Kim, T. Murata, Y. A. Kang, Y. Ohkoshi, Y. Gotoh, M. Nagura, H. Urakawa, 
Macromolecules, 44 (2001) 7378.

[26] K. H. Kim, T. Yamaguchi, Y. Ohkoshi, Y. Gotoh, M. Nagura, H. Urakawa, M. Kotera, T. Kikutani, J. Polym. Sci.: Part B: Polym. Phys., 47 (2009) 1653.

[27] U. Gaur, A. Mehta, B. Wunderlich, J. Therm. Anal., 13 (1978) 71.

[28] S. Kase, T. Matsuo, J. Polym. Sci. Part A, Gen. Pap., 3 (1965) 2541.

[29] R. de, P. Daubeny, C. W. Bunn, Proc. R. Soc. London Ser. A, 226 (1954) 531.

[30] Yu. Ya. Tomashpol'skii, G. S. Markova, Polym. Sci. U. S. S. R., 6 (1964) 316.

[31]S.Nakahama, Fundamental and Practical Technologies for Nano-structured Polymeric Materials, CMC Publishing, 2008, 66.

[32] J. Shimizu, T. Kikutani, A. Takaku, N. Okui, Sen’i Gakkaishi, 40 (1984) T177.

[33] J. Shimizu, N. Okui, T. Kikutani, Sen’i Gakkaishi, 37 (1981) T135.

[34] K. Okada, M. Nakada, T. Higashioji, K. Takahashi, Y. Ohkoshi, T. Kanaya, Kobunshi Ronbunshu, 71 (2014) 593.

[35] E. Funai, S. Sakurai, S. Hara, K. Yamamoto, S. Okamoto, J. Kojima, T. Kikutani, Sen'i Gakkaishi, 60 (2004) 322. 


\section{Figure Captions}

Figure 1 Schematic diagram of the in-situ measurement system.

Figure 2 Estimated fiber temperature profiles.

Figure 3 (a) WAXD patterns taken at various elapsed times after necking. (b) The enlarged pattern for $\mathrm{H}-\mathrm{H} 0.51 \mathrm{~ms}$.

Figure 4 WAXD intensity profiles along the (a) meridional and (b) equatorial directions for L-H.

Figure 5 Integrated intensities of smectic (001') diffraction.

Figure 6 d-spacing of the (001') planes.

Figure 7 Crystallinity index estimated from the equatorial intensity profiles.

Figure 8 Crystallite sizes along the (a) (010), (b) (-110), and (c) (100) directions

Figure 9 Crystal orientation factor obtained from (a) (010), (b) (-110), and (c) (100) diffractions.

Figure 10 Tilting angle obtained from (a) (010) and (b) (100) diffractions.

Figure 11 SAXS patterns taken at various elapsed times after necking.

Figure 12 Typical SAXS intensity layer-line profile passing through the peak of 4-point pattern, L-H at $2.0 \mathrm{~ms}$. The Gaussian fitting curves are also shown.

Figure 13 Intensity fraction of the 2-point pattern obtained from the SAXS layer-line profile passing through the intensity peak of the 4-point pattern. 
Figure 14 Peak position of SAXS 4-point patterns shifted with elapsed times of up to $2.0 \mathrm{~ms}$. 


\section{Table 1 Drawing conditions}

\begin{tabular}{|c|c|c|c|c|c|c|c|c|}
\hline \multirow[b]{2}{*}{ Condition } & \multirow[b]{2}{*}{ Polymer } & \multirow[b]{2}{*}{ NDR } & \multirow[b]{2}{*}{$\begin{array}{c}\text { Draw } \\
\text { ratio }\end{array}$} & & \multirow[b]{2}{*}{$\begin{array}{l}\text { Position } \\
\text { resolution } \\
\text { / mm }\end{array}$} & \multirow[b]{2}{*}{$\begin{array}{c}\text { Time } \\
\text { resolution } \\
\text { / ms }\end{array}$} \\
\hline & & & & $\begin{array}{c}\text { Feed speed } \\
/ \mathrm{m} / \mathrm{min}\end{array}$ & $\begin{array}{l}\text { Laser } \\
\text { power } \\
\text { / W }\end{array}$ & $\begin{array}{c}\text { Drawing } \\
\text { stress } \\
\text { / MPa } \\
\end{array}$ & & \\
\hline L-L & I DET & 20 & 4.3 & 25 & 17 & 43 & 0.21 & 0.12 \\
\hline L-H & L-PE1 & 3.0 & 5.2 & 21 & 18 & 103 & 0.17 & 0.09 \\
\hline H-L & & & 3.8 & 28 & 19 & 49 & 0.21 & 0.12 \\
\hline $\mathrm{H}-\mathrm{H}$ & Н-PEТ & 3.4 & 4.8 & 23 & 21 & 148 & 0.19 & 0.10 \\
\hline S-L & PS/L- & & 4.3 & 25 & 17 & 89 & 0.18 & 0.10 \\
\hline S-H & PET & 3.8 & 5.0 & 22 & 18 & 133 & 0.17 & 0.09 \\
\hline
\end{tabular}


Table 2 Birefringence and properties of as-spun and drawn fibers.

\begin{tabular}{|c|c|c|c|c|c|c|c|c|c|}
\hline Sample & $\Delta \mathrm{n}$ & $\begin{array}{l}\text { Strength } \\
\text { / cN/dtex }\end{array}$ & $\begin{array}{l}\text { Elongation } \\
\qquad / \%\end{array}$ & $\begin{array}{l}\text { Young's } \\
\text { Modulus } \\
\text { / cN/dtex }\end{array}$ & $\begin{array}{c}\text { Cold- } \\
\text { Crystallization } \\
\text { Temp. } \\
{ }^{\circ} \mathrm{C}\end{array}$ & $\begin{array}{l}\text { Melting } \\
\text { Temp. } \\
\quad /{ }^{\circ} \mathrm{C}\end{array}$ & $\begin{array}{l}\text { Crystallinity } \\
\qquad / \%\end{array}$ & $\begin{array}{l}\text { Max. } \\
\text { Shrinkage } \\
\text { Stress } \\
\text { / cN/dtex }\end{array}$ & $\begin{array}{c}\text { Max. } \\
\text { Shrinkage } \\
\text { Temp. } \\
\quad{ }^{\circ} \mathrm{C}\end{array}$ \\
\hline L-As-spun & 0.008 & 1.0 & 543 & 13.1 & 135.8 & 254.3 & 21 & 0.00 & 82 \\
\hline L-L & 0.17 & 5.0 & 48.7 & 57.6 & - & 252.8 & 47 & 0.27 & 147 \\
\hline L-H & 0.19 & 6.1 & 22.5 & 81.1 & - & 253.6 & 60 & 0.52 & 176 \\
\hline H-As-spun & 0.010 & 1.3 & 507 & 12.3 & 139.5 & 253.1 & 10 & 0.00 & 82 \\
\hline $\mathrm{H}-\mathrm{L}$ & 0.16 & 5.0 & 36.6 & 53.3 & - & 255.0 & 50 & 0.30 & 158 \\
\hline $\mathrm{H}-\mathrm{H}$ & 0.18 & 7.5 & 26.5 & 83.1 & - & 251.9 & 56 & 0.51 & 194 \\
\hline S-As-spun & - & 0.6 & 387 & 12.6 & 130.5 & 256.4 & 35 & 0.01 & 79 \\
\hline S-L & - & 5.2 & 39.7 & 71.3 & - & 254.9 & 70 & 0.38 & 167 \\
\hline S-H & - & 6.2 & 20.2 & 89.6 & - & 254.9 & 73 & 0.71 & 183 \\
\hline
\end{tabular}




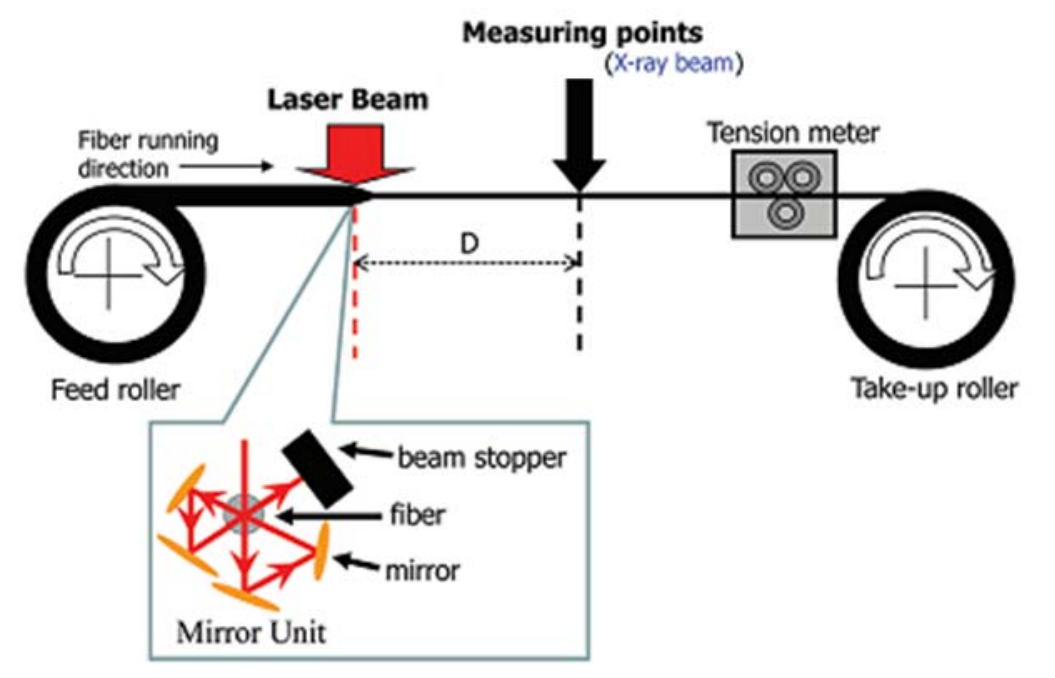

Figure 1. Schematic diagram of in-situ measurement system. 
Distance from necking point / mm

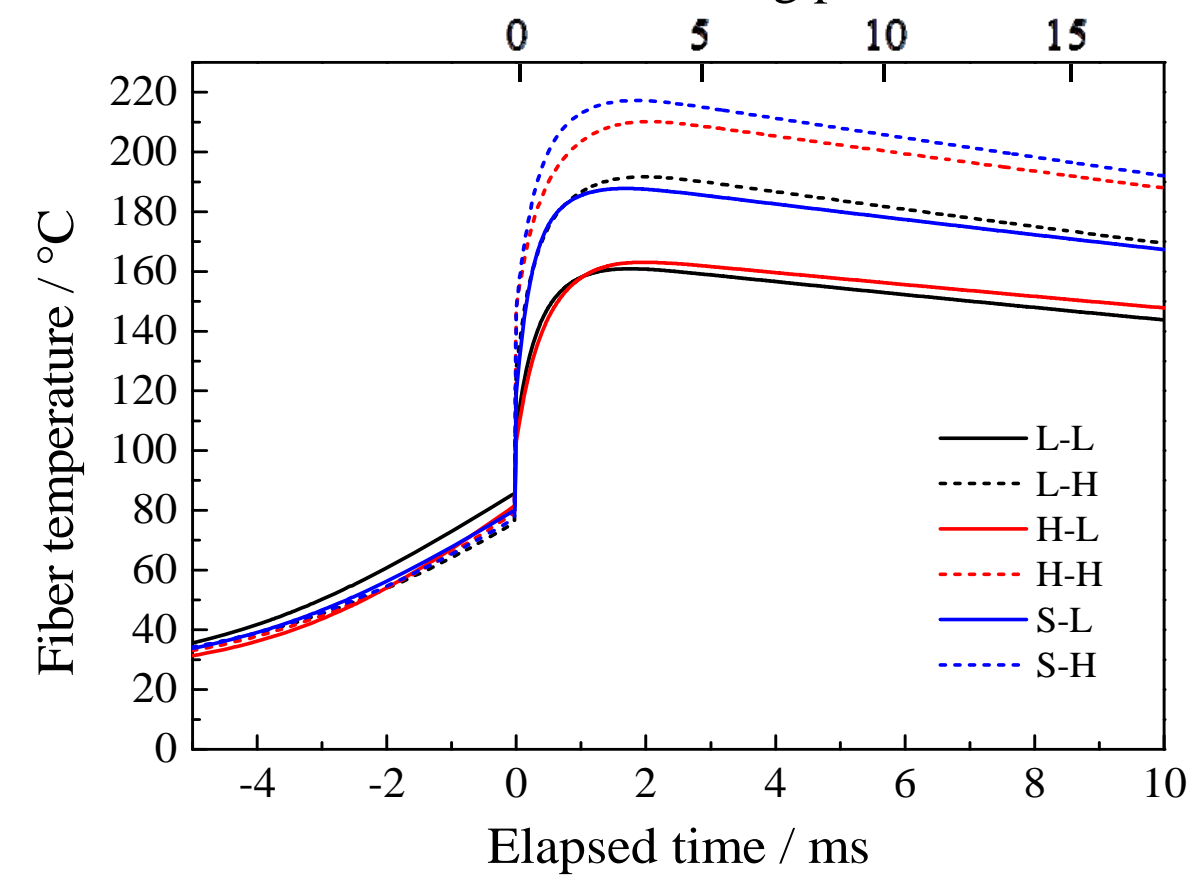

Figure 2. Estimated fiber temperature profiles. 


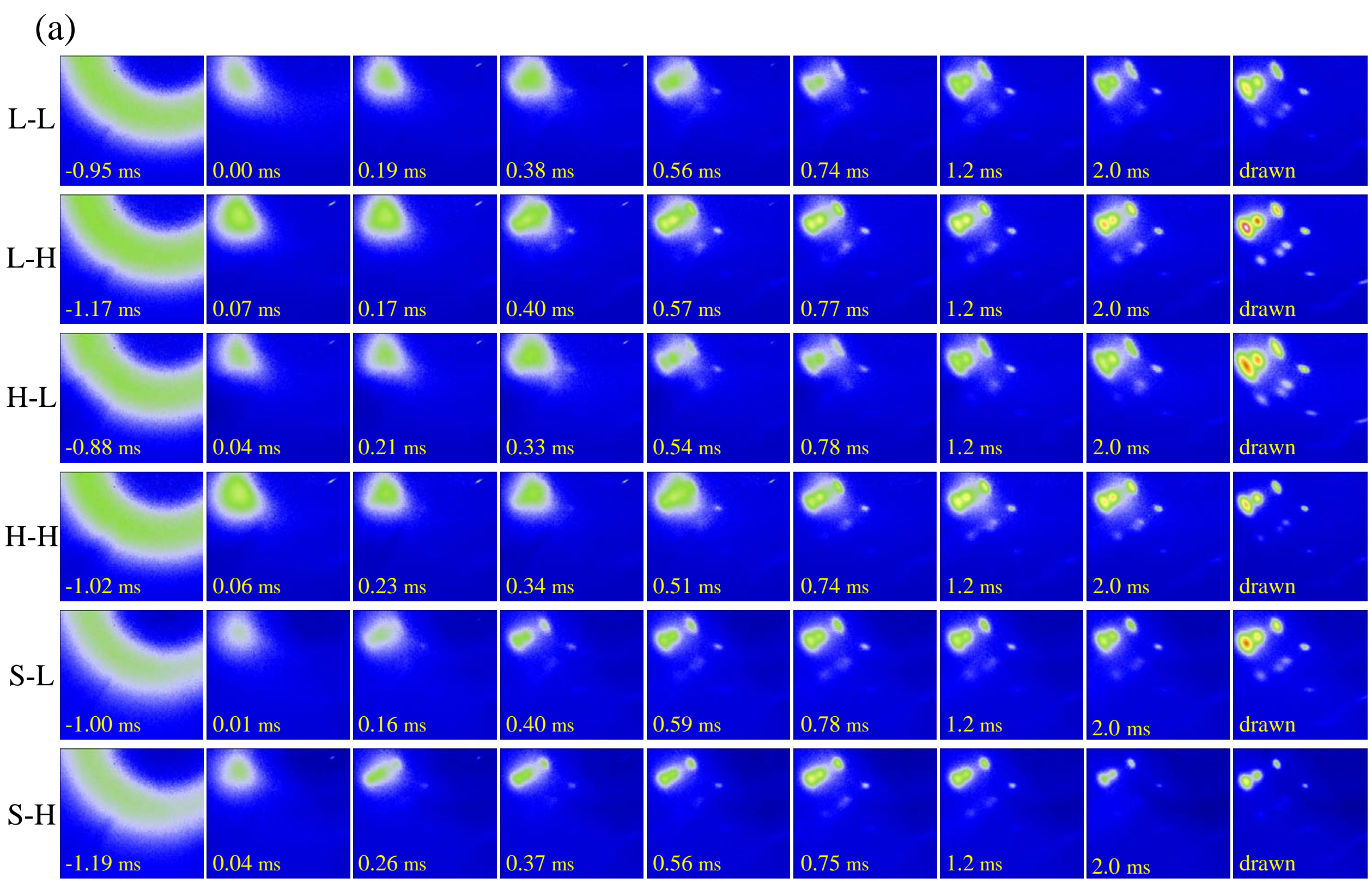




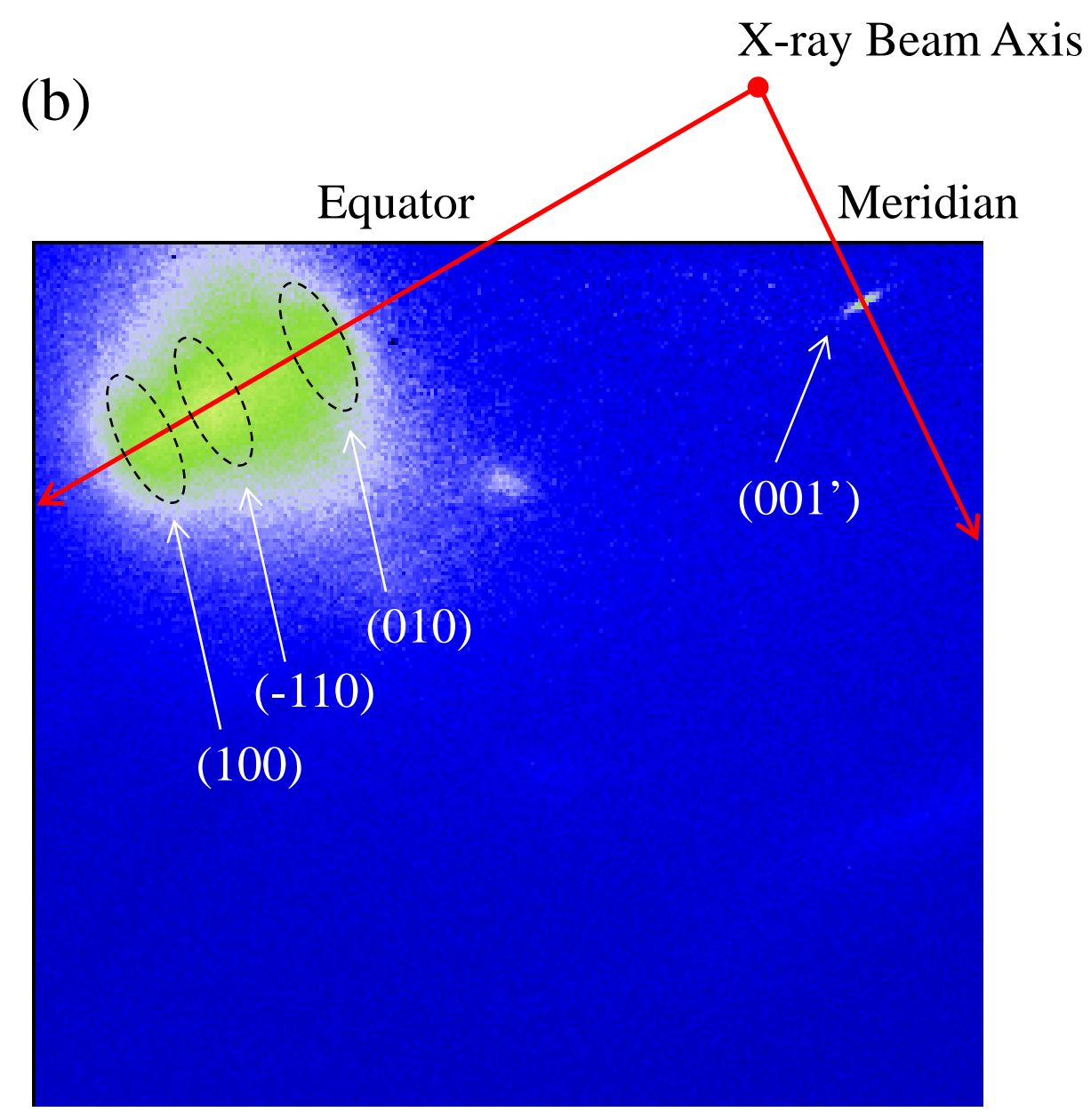

Figure 3. (a) WAXD patterns taken for various elapsed time after necking. (b) The enlarged pattern for $\mathrm{H}-\mathrm{H} 0.51 \mathrm{~ms}$. 
(a)

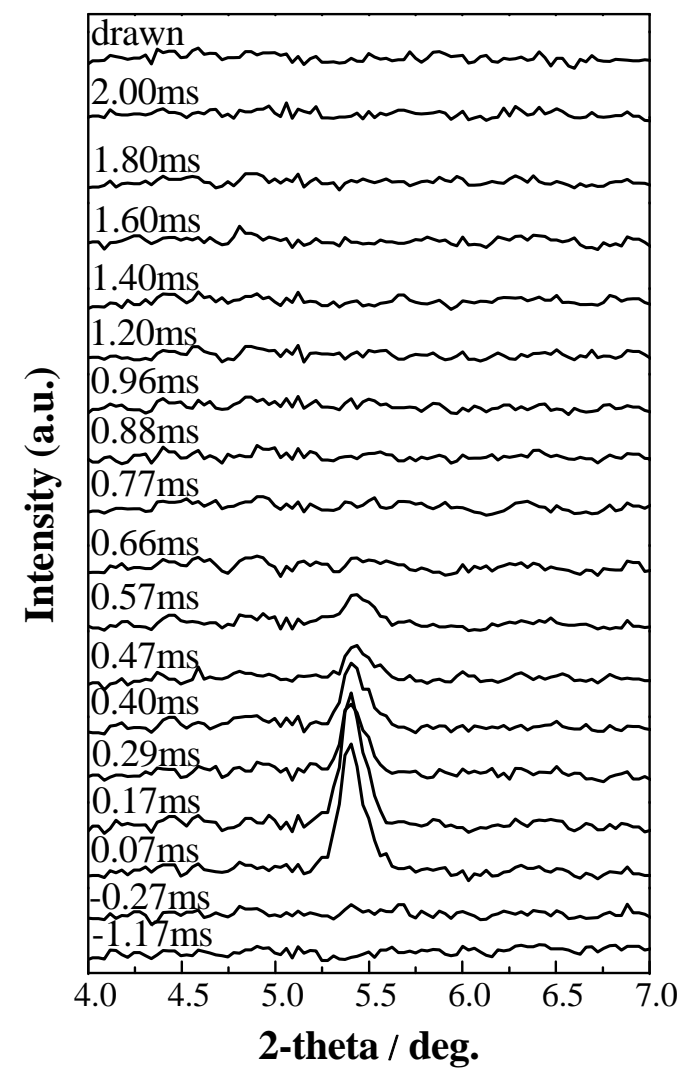

(b)

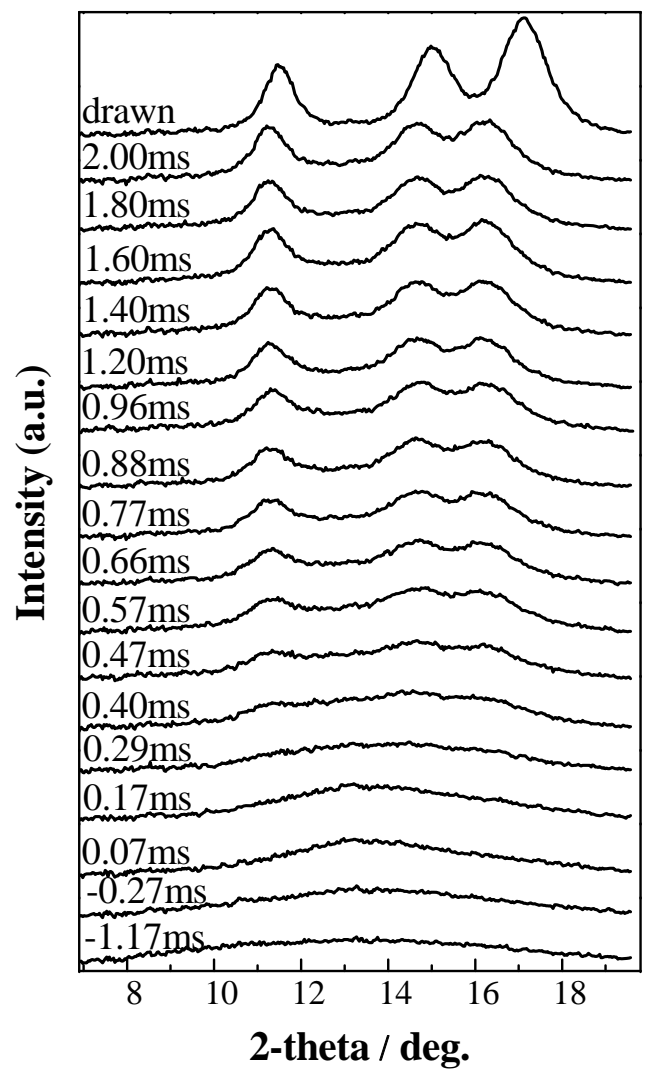

Figure 4. WAXD intensity profiles along the (a) meridional and (b) equatorial directions for $\mathrm{L}-\mathrm{H}$. 


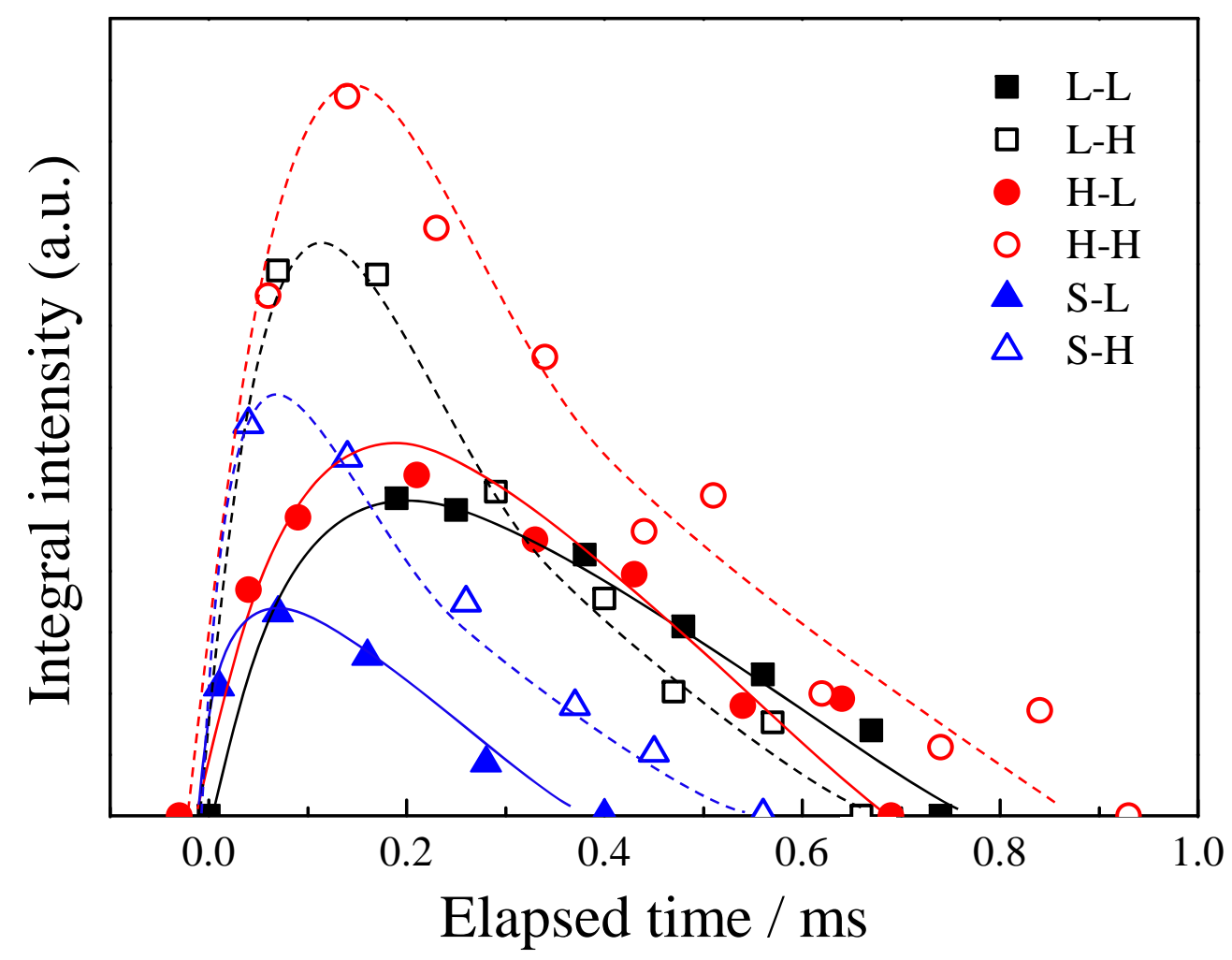

Figure 5. Integrated intensities of smectic (001’) diffraction. 


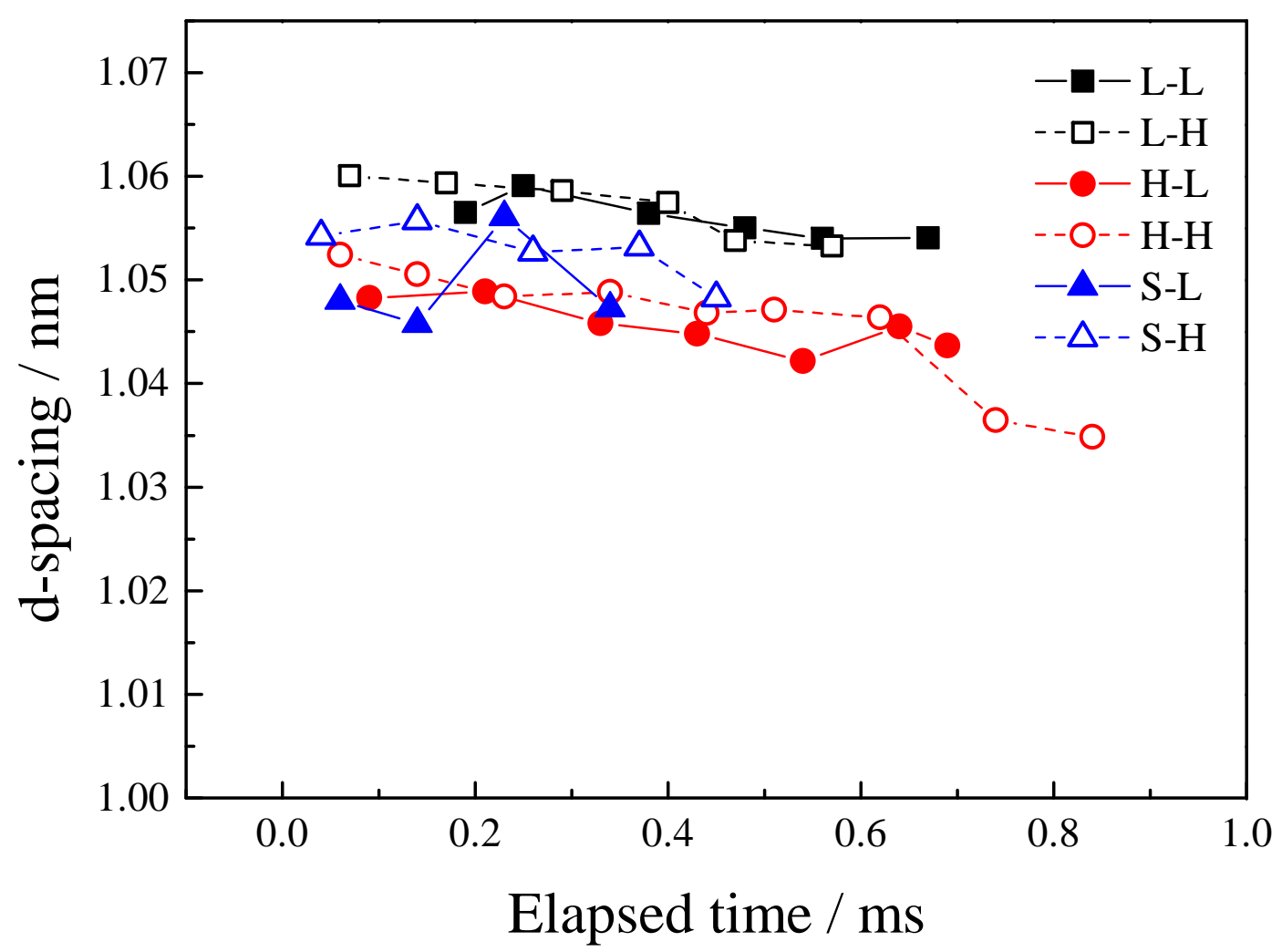

Figure 6. d-spacing of (001') plane. 


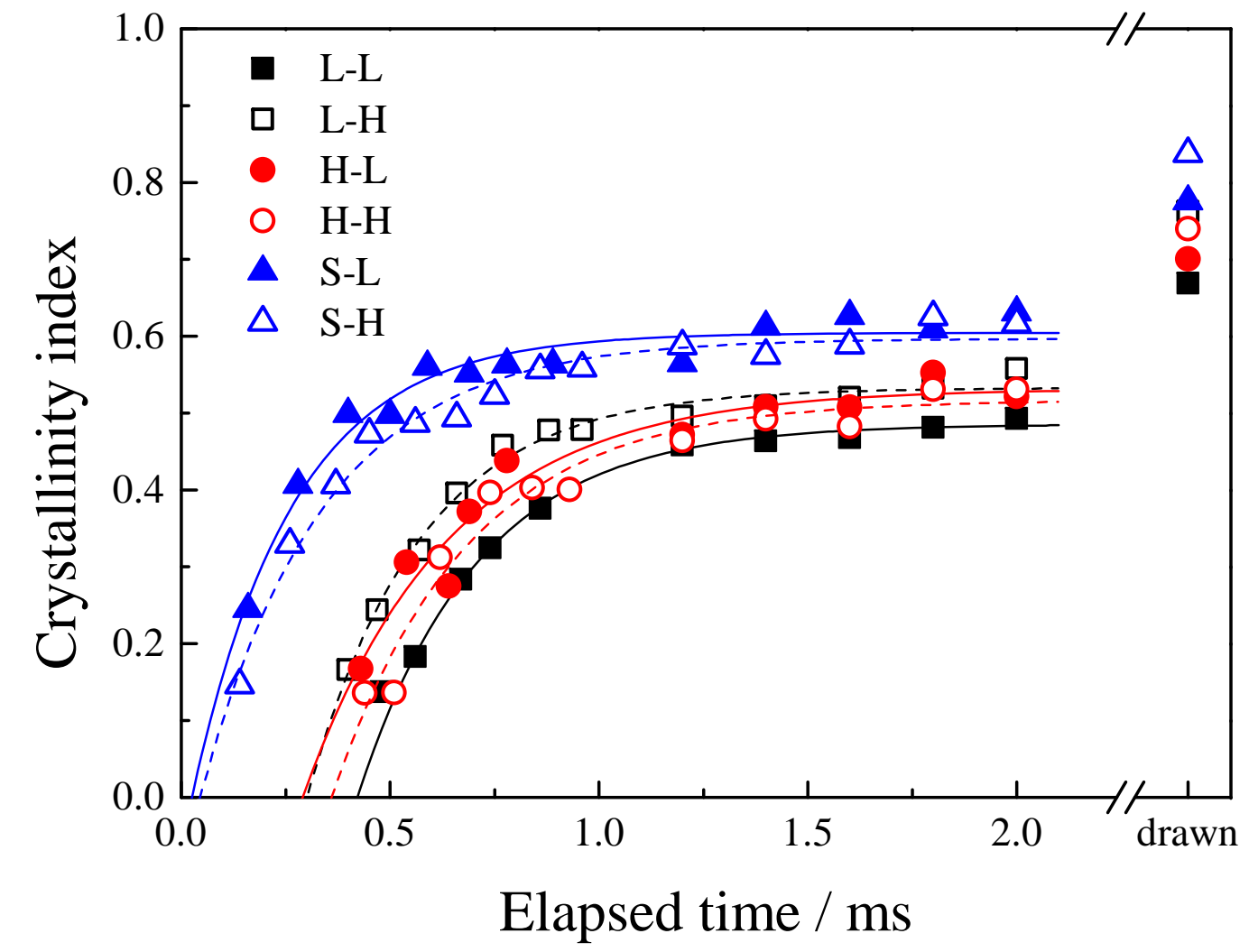

Figure 7. Crystallinity index estimated from the equatorial intensity profiles. 
(a)

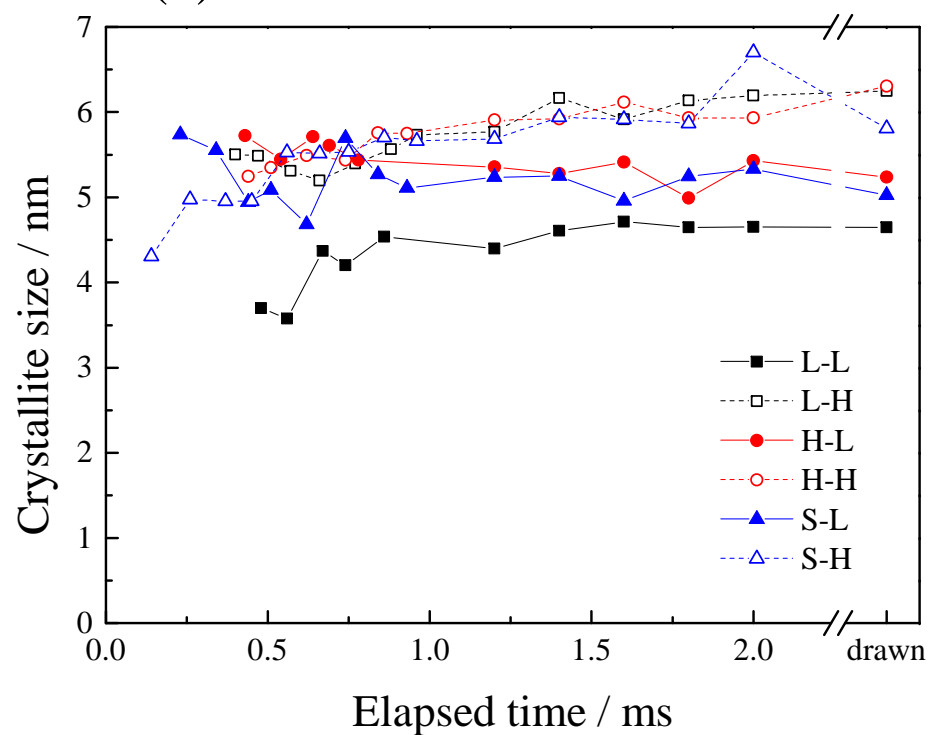

(c)

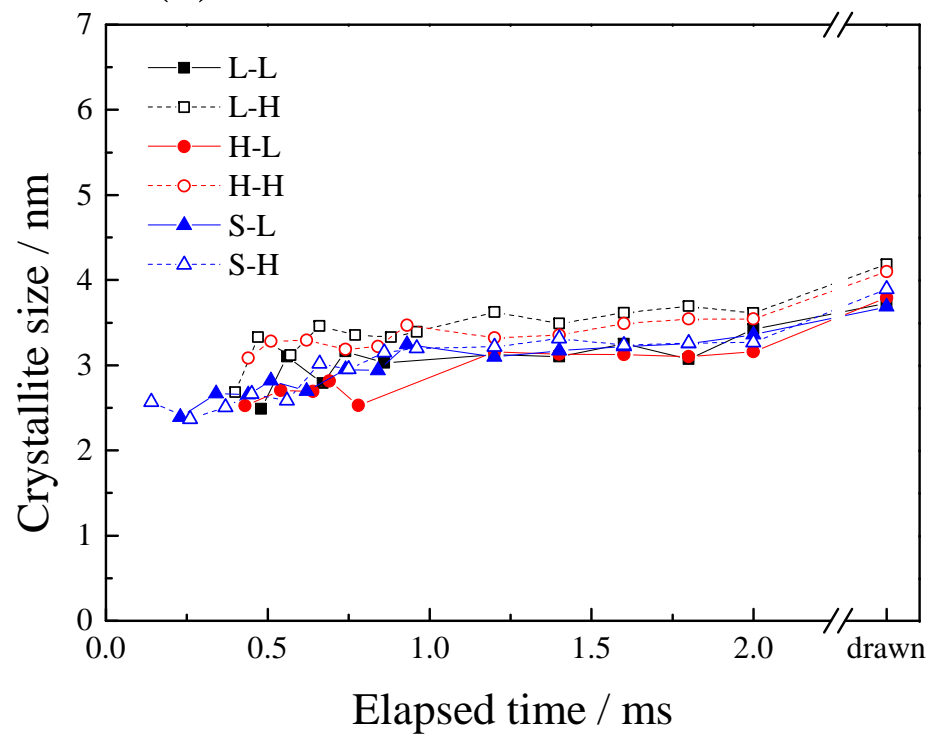

(b)

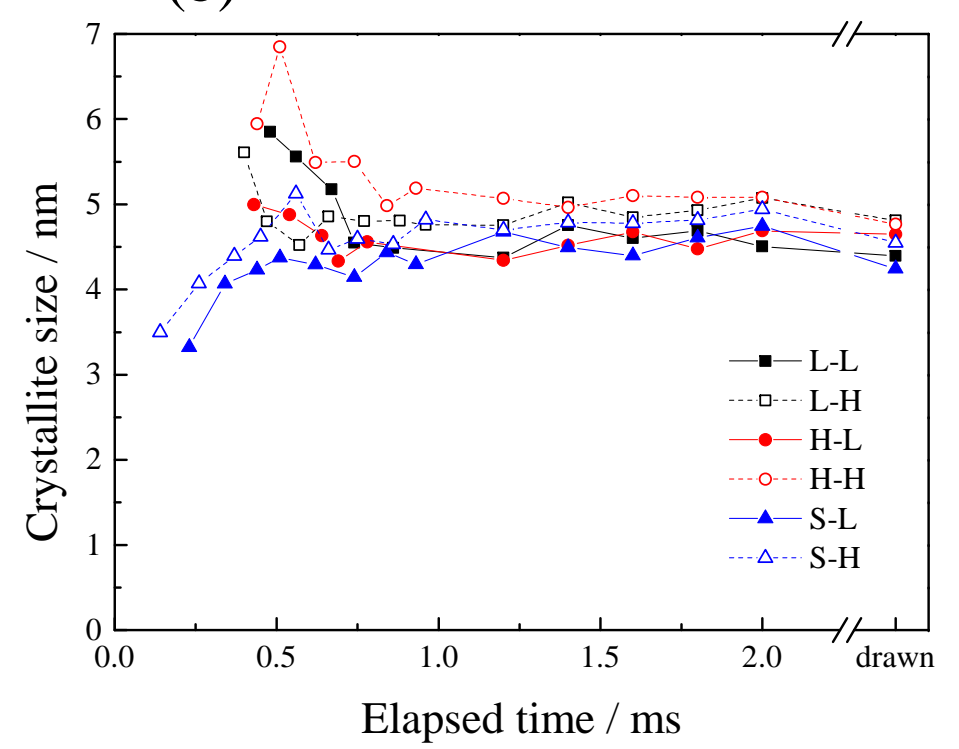

Figure 8. Crystallite sizes along the (a) (010), (b) $(-110)$ and (c) (100) directions. 
(a)

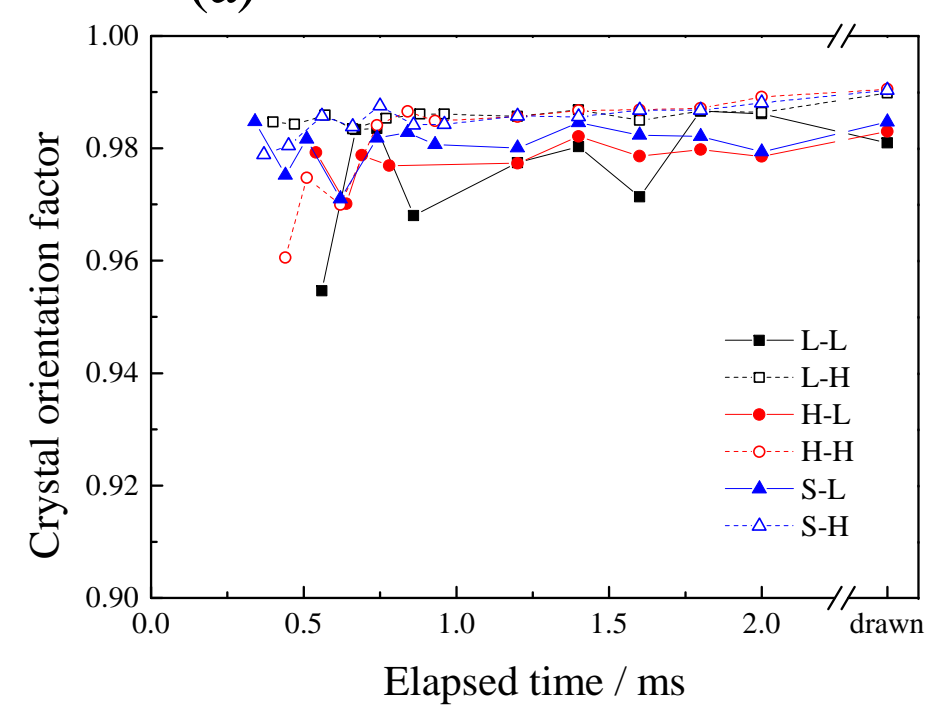

(c)

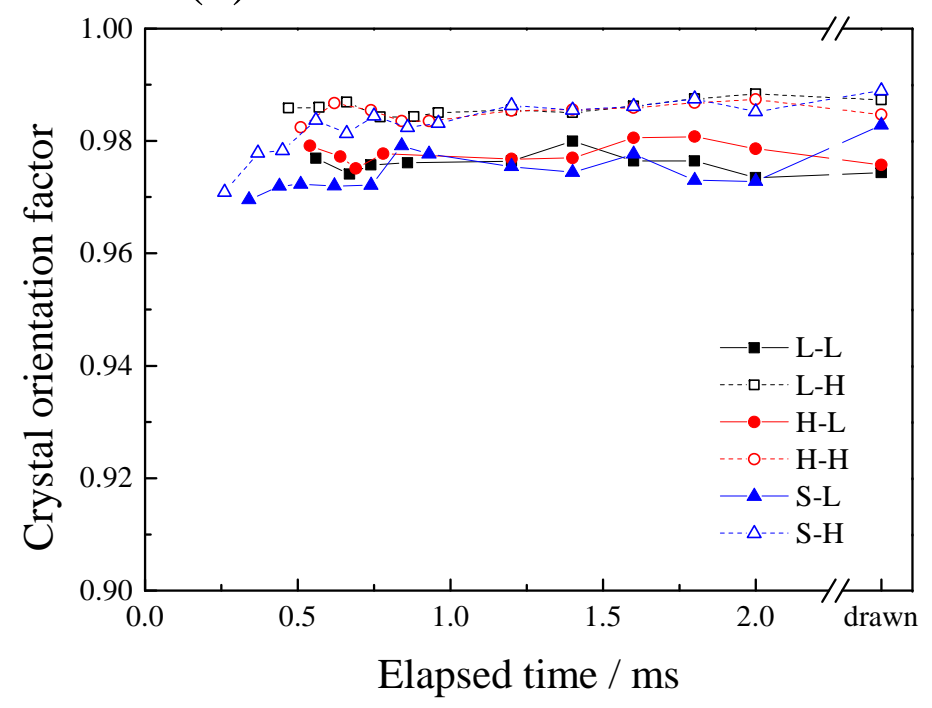

(b)

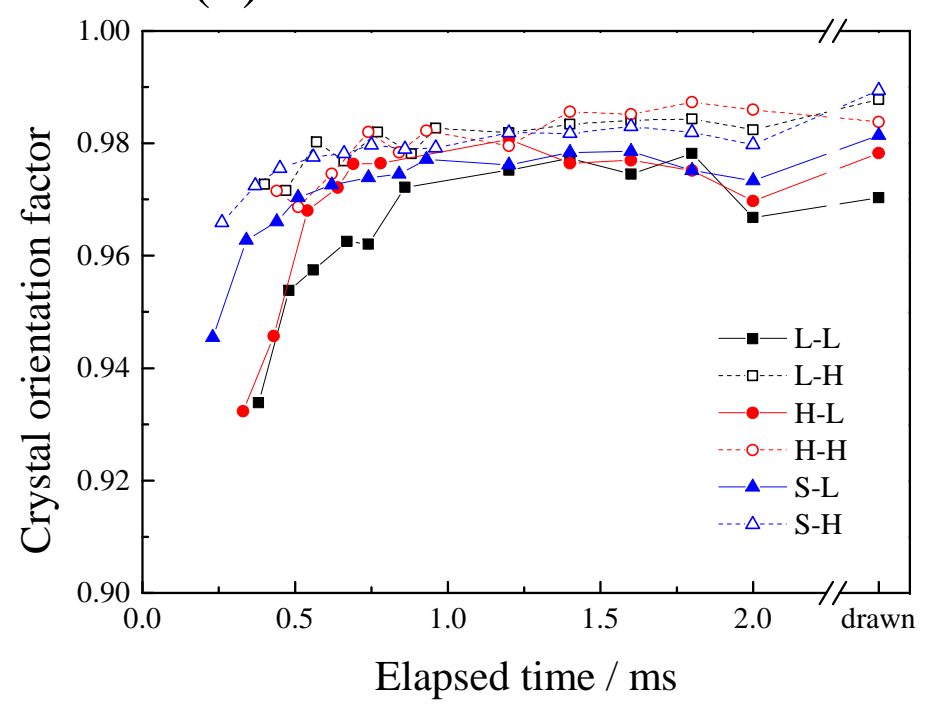

Figure 9. Crystal orientation factor obtained by (a) (010), (b) (-110) and (c) (100) diffractions. 
(a)

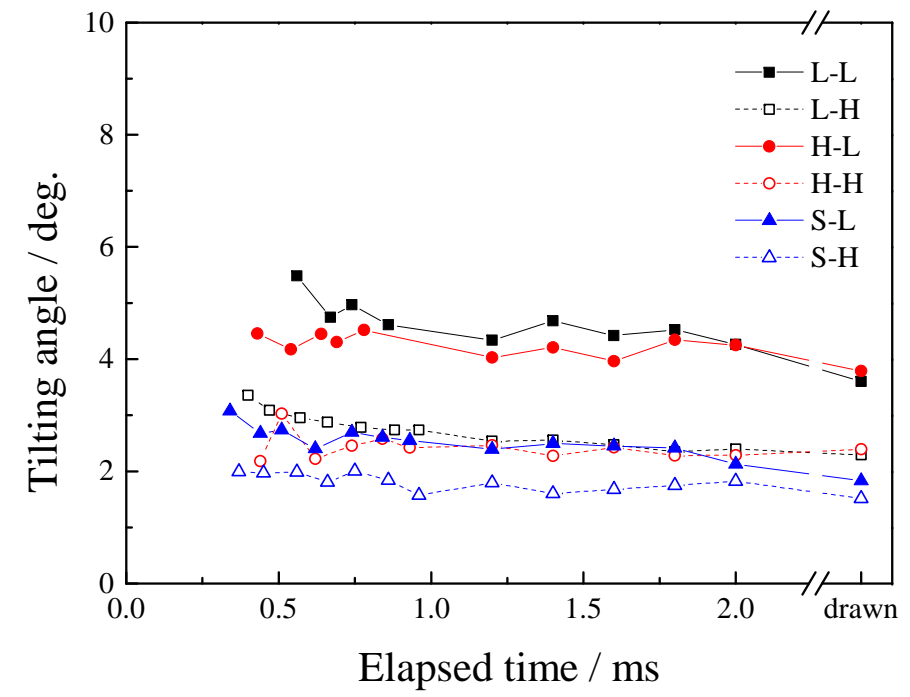

(b)

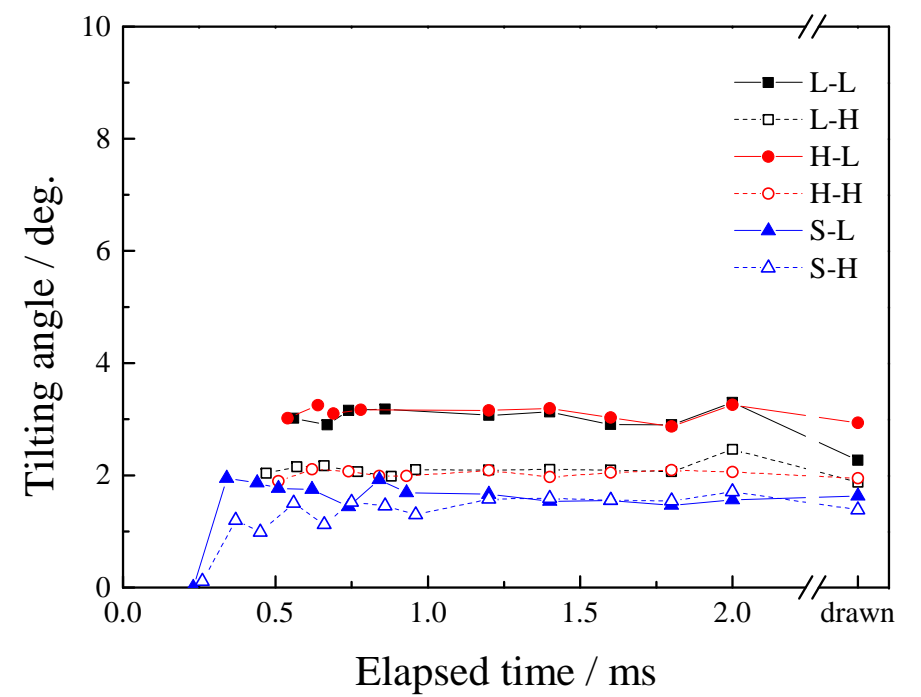

Figure 10. Tilting angle obtained by (a) (010) and (b) (100) diffractions. 


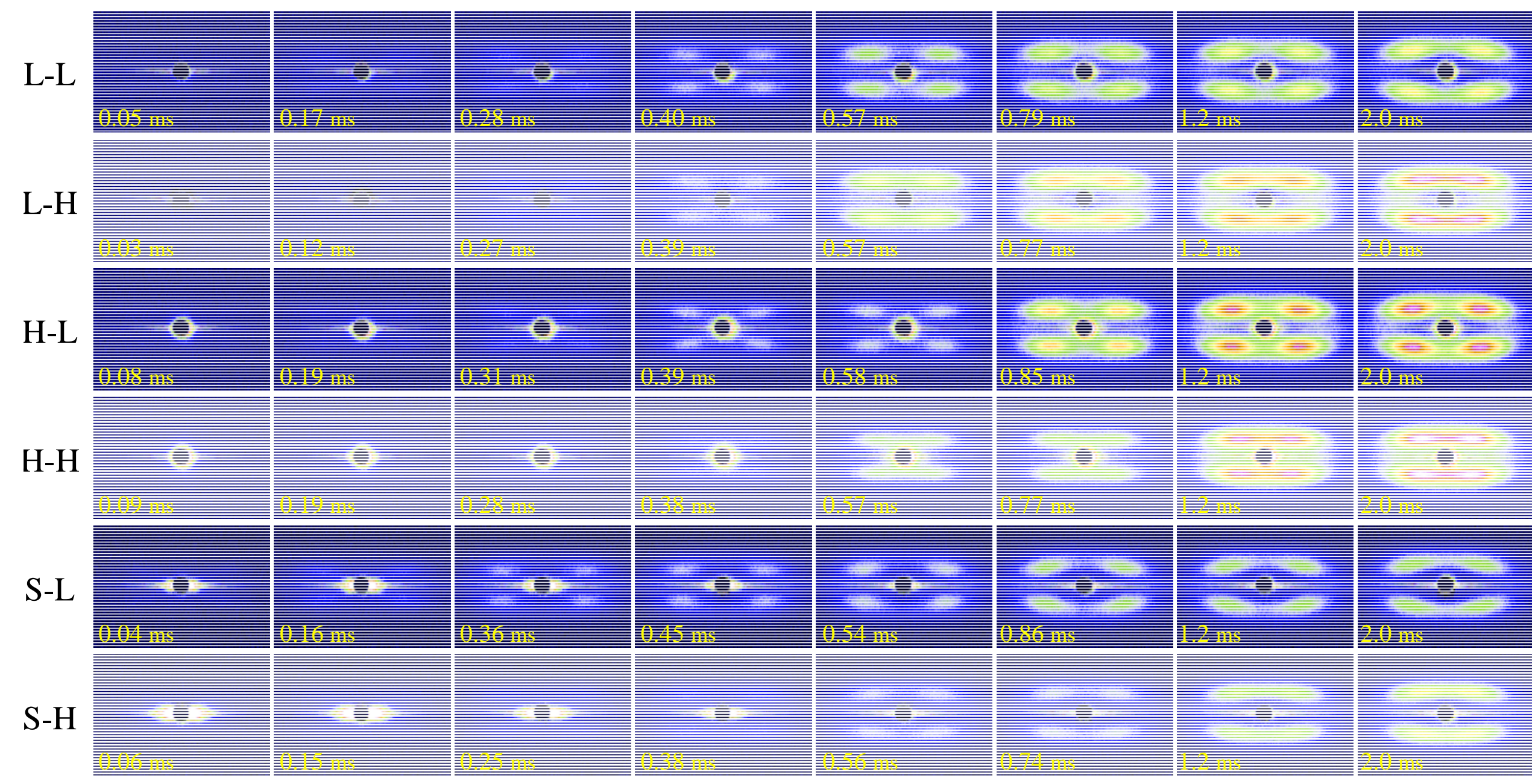

Figure 11. SAXS patterns taken for various elapsed time after necking. 


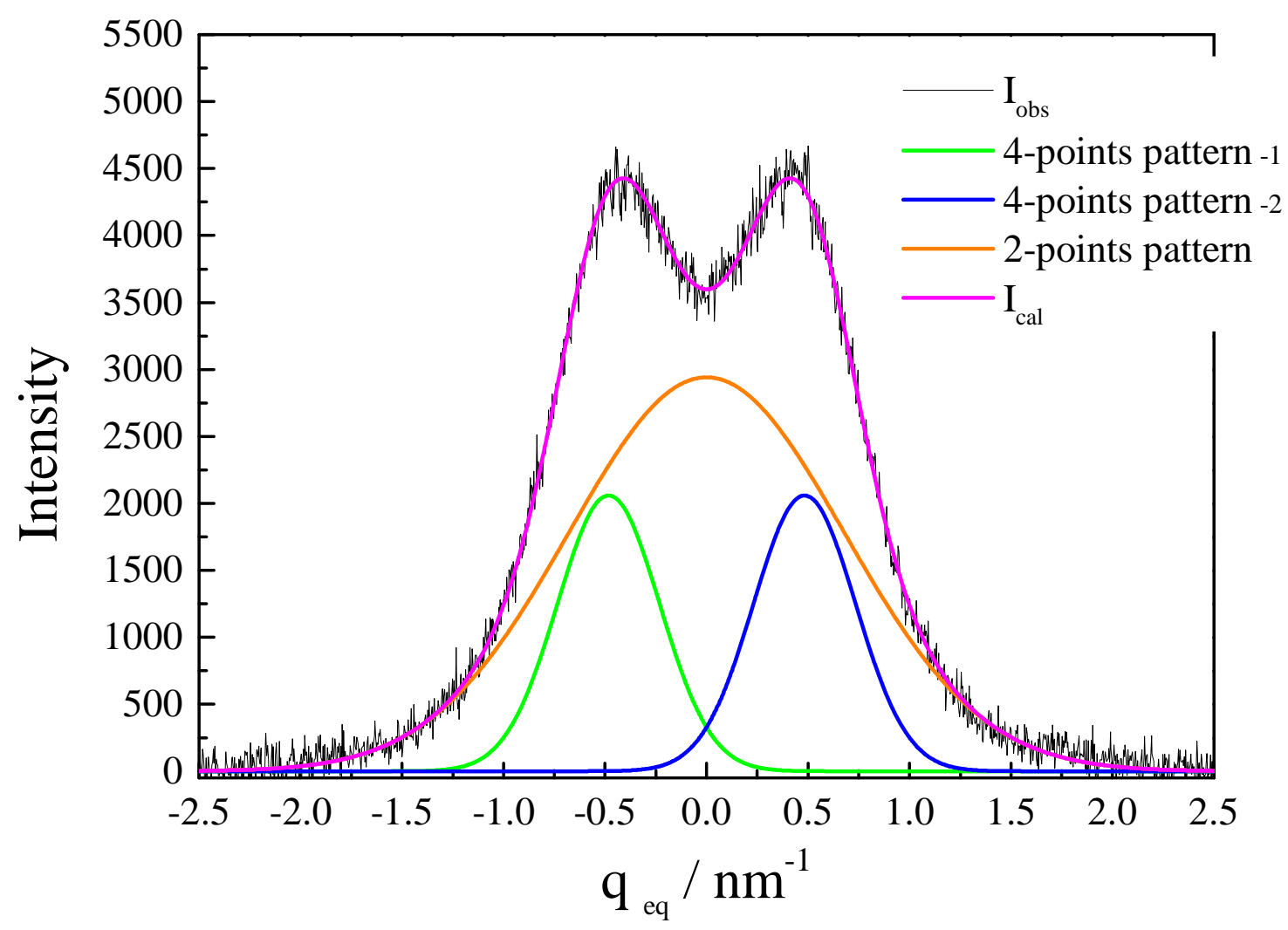

Figure 12. Typical SAXS intensity layer-line profile passing through the 4-points pattern, $\mathrm{L}-\mathrm{H}$ at $2.0 \mathrm{~ms}$. The Gaussian fitting curves are also shown. 


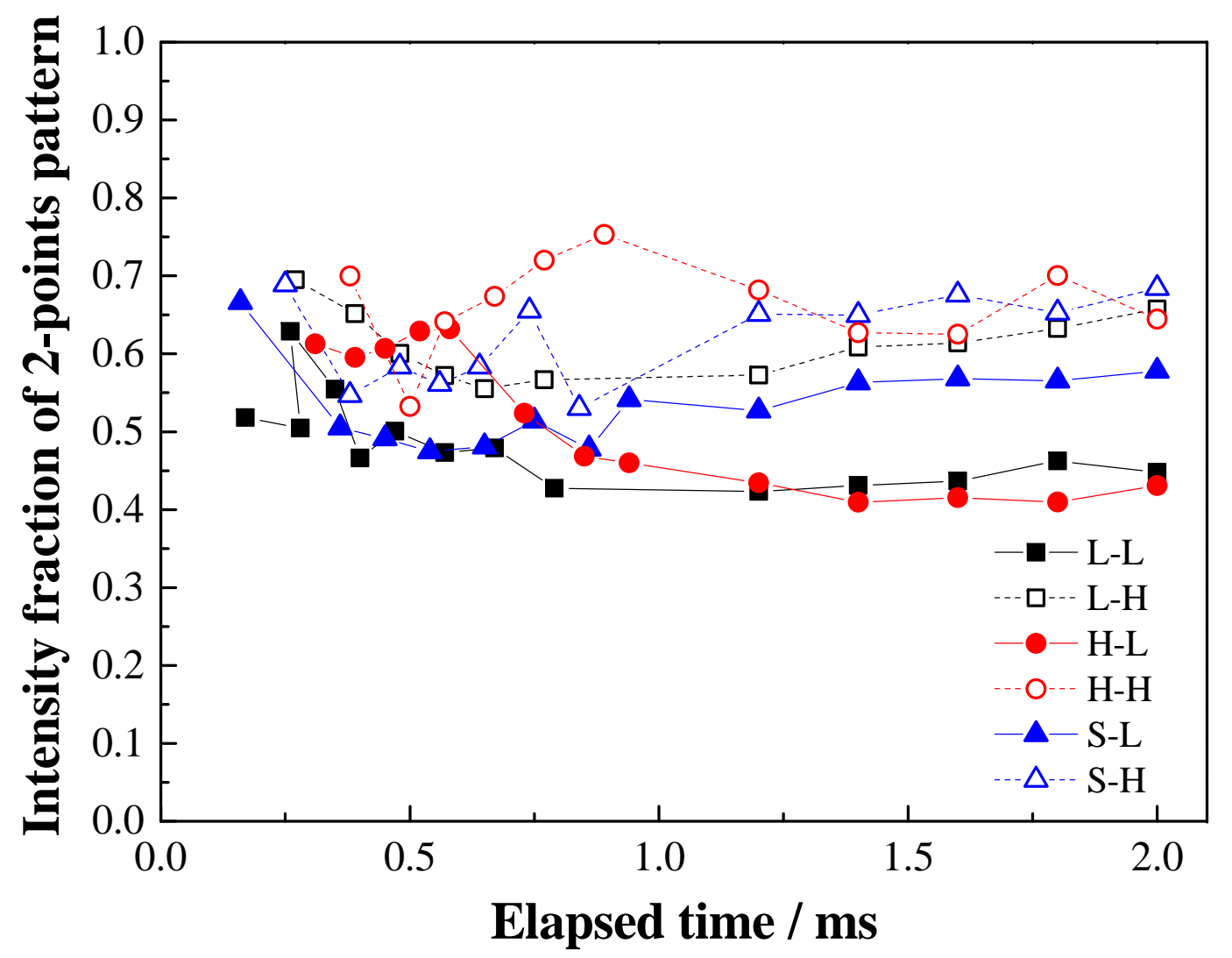

Figure 13. Intensity fraction of 2-points pattern obtained for the SAXS layer-line profile passing through the intensity peak of 4-points pattern. 


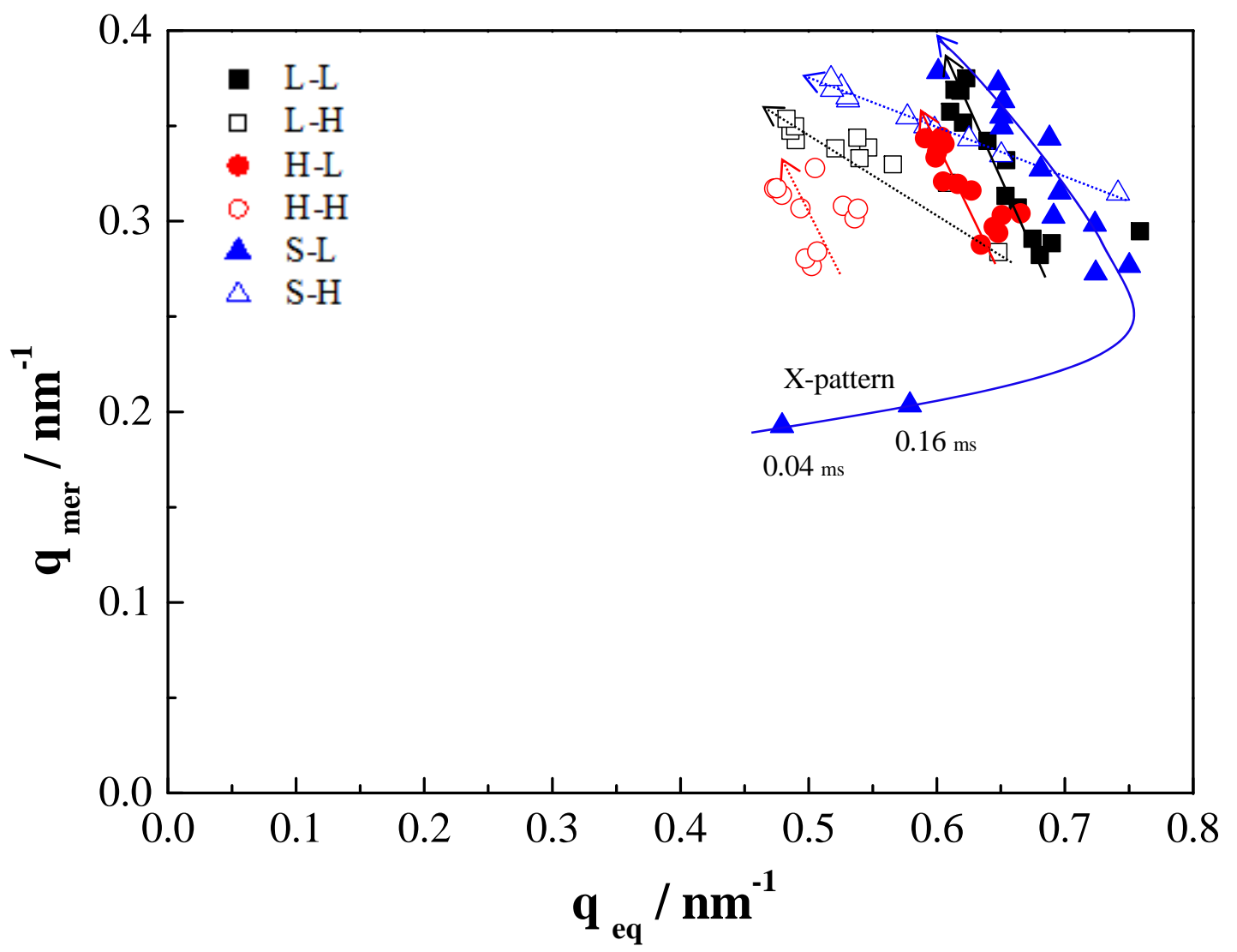

Figure 14. Peak position of SAXS 4-points patterns shifted with the elapsed time up to $2.0 \mathrm{~ms}$. 